$\begin{array}{r}\text { Volume and Issues Obtainable at Center for Sustainability Research and Consultancy } \\ \text { Journal of Business and Social Review in Emerging Economies } \\ \text { ISSN: 2519-089X (E): 2519-0326 } \\ \text { Volume 6: No. 4, December } 2020 \\ \text { JSRᄃ } \\ \text { Journal homepage: www.publishing.globalcsrc.org/jbsee } \\ \hline\end{array}$

\title{
International ESL Students' Experiences and Perceptions of Effective and Constructive Feedback Practises on their Academic Writing in MA Programme
}

\author{
${ }^{1}$ Marukh Shakir, ${ }^{2}$ Mujahid Shah, ${ }^{3}$ Munir Khattak \\ ${ }^{1}$ Assistant Professor, Abdul Wali Khan University Mardan, Pakistan \\ ${ }^{2}$ Assistant Professor, Abdul Wali Khan University Mardan, Pakistan, mujahidshah@awkum.edu.pk \\ ${ }^{3}$ Assistant Professor, Department of English, University of Labella, Pakistan

\begin{tabular}{l}
\hline ARTICLE DETAILS \\
\hline History \\
Revised format: November \\
2020 \\
Available Online: December \\
2020 \\
\hline Keywords \\
ESL students, Academic \\
Writing, MA Programme, \\
Effective, Constructive \\
\hline
\end{tabular} \\ JEL Classification \\ MO, M10

\begin{abstract}
This paper investigates students' experiences, perceptions, understanding and interpretation of different types of feedback. For this purpose, qualitative interviews were conducted from ten ESL (not having English as their native language) students regarding different types of feedback that had they received on their academic assignments; the effects and potential of those feedback on their learning and writing, and the factors causing difficulties in their effective use of those feedback. According to the findings, all participants expressed their satisfaction with support in the form of feedback in improving their academic writing but also showed some reservations in effectively exercising them. The findings revealed that the interviewees received feedback in varied modes, however, mostly in written form; from tutors; and after the submission of assignments, and less in oral form; from peers; during the writing processes; and before the submission of assignments. Conclusions are drawn and limitation and suggestions for future research are addressed in the light of the findings.
\end{abstract}

(C) 2020 Center for Sustainability Research and Consultancy Pakistan under a Creative Commons Attribution-NonCommercial-ShareAlike 4.0

Corresponding author's email address: mujahidshah@awkum.edu.pk

Recommended citation: Shakir, M., Shah, M. \& Khattak, M. (2020). International ESL Students' Experiences and Perceptions of Effective and Constructive Feedback Practises on their Academic Writing in MA Programme.. Journal of Business and Social Review in Emerging Economies, 6(4), 1401-1413

\section{Introduction}

The significant, central and decisive role of feedback in L2 writing field for the development of student learning process, their motivation and writing skills related to L2 has been widely recognised in L2 writing field (Hounsell, 2003; K. Hyland \& F. Hyland, 2006). Ramsden (2003) opines that effective comments on students' work are indicative of quality teaching. Hounsell (2003: 67) states that we learn faster, and much more effectively, when we have a clear sense of how well we are doing and what we might need to do in order to improve'. Gibbs \& Simpson (2004) highlighted the significance of feedback being timely, understandable and acted upon by students. 
Feedback is a significant and primary aspect of EFL/ESL writing programs around the world. The research studies are not clearly positive regarding the role of feedback in L2 writing development (K. Hyland \& F. Hyland, 2006). It is usually viewed by teachers that its full potential is not made use of by them (ibid). Students are mostly dissatisfied with the feedback they get because they either find it difficult to interpret it (Chanock, 2000), lacking specific advice to improve (e.g. Higgins et al., 2001), or it has a potentially adverse effect on students' confidence and self-perception (James, 2000). Inspired by such feedback-oriented research and a recommendation by Poverjuc (2011) for future research to investigate the students' perceptions of effective feedback practises on academic writing, I conducted a small-scale empirical research based on the students' interviews (explained in detail later). This provided me with an opportunity to compare my findings with the previous feedback oriented research, and thus offered the basis for stronger conclusions and suggestions for improving students' long term writing skills. It also helped me in examining the relevance of feedback in another context (Higher Education context in UK). Moreover, it helped me identify new variables that may affect them. It must be kept in mind that this paper only deals with feedback for writing tasks; so wherever feedback is mentioned, the context is exclusively that of written work.

\subsection{The Current Study}

Feedback is a social process that may be interpreted in different ways (Carless, 2006). This study examines the value of feedback in terms of informing students about their academic performance (though not in terms of correcting their writing), in terms of students' experiences and perceptions of different types of feedback they receive in different modes during their master's course, in terms of the difficulties they faced while they have engaged with those feedbacks, and in terms of their perceptions of effective feedback for improving their writing skills. In other words, to explore and exemplify how international ESL students experience, perceive, understand and interpret the assignments feedback process, the different modes of feedback in this study refers to the input and responses that students receive on or about their academic assignments from their tutors in the form of;

- Written remarks on the drafts or finalised assignments.

- Any verbal feedback (e.g. during the development of ideas) prior to or after the submission of assignments.

- Feedback in different modes such as explicit/implicit, oral/written, and specific/detailed.

The motivation for this study also comes from my personal experiences during my M.A in Applied Linguistics, from feedback I received about assignments, and from talking to peers about it. I experienced that in majority of cases in M.A, students do not get feedback, which has the potential to allow them to revise the draft paper. Mostly they get feedback after the submission of assignments which may undermine the basic purpose of feedback. Most importantly, in my opinion, the value of feedback lies in utilising the feedback constructively for development e.g. when students get feedback what do they do with that feedback? Where does it go? What is its value for them? What do they think of it?

\section{Literature Review}

Feedback, in educational context, is usually conceptualized as fulfilling both 'evaluative' and 'educative' functions (Dochy\& McDowell 1997). From an evaluative perspective, feedback provides students with information regarding her/his performance attempt at a task (Hounsell, 1987). In terms of educative function, feedback supports students' development and facilitates task improvement (Hester 2001). Fleming (1999) contends that marking student scripts is an important quality event in students' lives. Such feedback can have various functions such as an advice for improving the current assignment, advice for improving the following assignments and justifying or explaining a grade (Carless, 2006). Tutors invest quite a lot of time in the feedback of this nature but the important point is to ask: what are the impact of such feedback on students and how might they relate to further learning? (ibid). According to Carless, students are usually motivated by and interested in marks and they do not bother much about the written feedback they get on their papers after submission of assignments (Carless, 2006). Feedback 
on assignments might have quite variable and mostly unpredictable effects on students (Lizzio\&Keithia, 2008). Young (2000) has identified the "potentially problematic nature of students' personal reactions to feedback on assignments" (e.g. decrease in self-esteem, academic confidence) in higher education context.

\subsection{Students' Perceptions of Feedback on Academic Assignments}

Students acknowledge feedback on assignments as important in the identification of their weaknesses and strengths, enhancement of motivation and improvement of their future grades (F. Hyland, 2000). Research reveals significant findings with regard to the nature of feedback which encompasses direct versus indirect feedback, written versus oral feedback, form versus content, combined and detailed feedback as explained ahead.

Regarding direct versus indirect feedback, in a study Ferris (2006) discovered that students used direct feedback more effectively and consistently than indirect feedback, possibly as it simply involves copying the tutor's suggestions into the next draft of their papers(K. Hyland \& F. Hyland, 2006). Robb et al. (1986) found minimum long-term gains in case of indirect feedback as compared to direct feedback practices. Williams (2004) found more uptake of teacher's advice in terms of revisions when teacher's suggestions were explicit.

With regard to written and oral feedback, findings on students' feedback preferences mostly reveal that ESL students greatly value tutor's written feedback and continuously rate it more highly than oral feedback (Leki 1991; Enginarlar 1993; Ferris 1995). Gibbs and colleagues indicate, for instance, that students might not consider oral comments asfeedback as much as they do written comments (Gibbs et al., 2003).

In case of form and content feedback, although some findings indicate that students want tutor's feedback on their grammatical errors, most studies show that they want tutors to give them feedback on the ideas and content in their writing as well (Hedgcock\&Lefkowitz, 1996). Students also favour receiving written suggestions in combination with other sources such as conferences (Hedgcock \& Lefkowitz 1994).

When it comes to detailed feedback, Leki (2006), for instance, while looking at feedback received by L2 graduate students in a US university, interviewed students to seek their opinions regarding the value of written feedback in development of their academic literacy. Most students showed their desire to have even more detailed feedback, particularly one helping them in identifying problems and giving them information about academic expectations.

\subsection{Difficulties in Using Feedback and Constructive and Effective Feedback Practises}

Feedback contribution both in terms of its immediate effect on revisions to drafts and of students long term development of writing skills is still not very clear (K. Hyland \& F. Hyland, 2006). Some difficulties might pertain to the following reasons;

\subsection{Incomprehensibility of Feedback}

Students may misunderstand, misinterpret or ignore tutor's comments when revising drafts (Ferris 1995; Conrad \& Goldstein 1999). It might also happen that they may have understood the issues pointed out but are incapable of coming up with an appropriate revision(Ferris 1997; Conrad \& Goldstein 1999), sometimes causing them to simply delete the offending text to avoid the problems pointed out (F. Hyland 1998).

\subsection{Tutor's Language}

Higgins (2000) argues that mostly students are unable to understand and correctly interprets feedback 
comments. Feedback is usually delivered in an academic discourse (language in which teacher's comments is encoded) that is not completely accessible to students.

\subsection{Negative Feedback}

Negative feedback may have harmful effect on writer's (students) confidence (F. Hyland \& K. Hyland 2001). However, mostly tutors try to mitigate the impact of their comments and criticisms by using question forms, hedges which might promote a supportive pedagogical environment, though its indirect approach carries the risk that students may misinterpret or miss the point of the feedback (K. Hyland \& F. Hyland 2006).

\subsection{Cultural Issues}

It has been argued that some L2 learners experience cultural constraints about their "engaging informally with authority figures" such as tutors or critically analysing tutor's remarks, which might result in students unreflectively and passively incorporating the tutor's suggestions into their work (Goldstein \& Conrad 1990).

\subsection{A Review of Literature Identifies Certain Features of Effective Feedback Messages Such as 2.7.1 Feedback on Drafts}

Commentary on drafts might serve more immediate pedagogical goals i.e. development of writing as compared to that given on the final version (K. Hyland \& F. Hyland, 2006). Feedback on the drafts was utilised more by the students who tended to improve their papers, a conclusion reached by Ferris (1997) while looking at ESL students' first and second drafts of papers during his investigation into the relationship between teacher feedback and student revision. Zamel, for example, also endorses teachers' comments on ideas in earlier drafts (Zamel 1985). Higginset al. (2002) contends, 'feeding forward' increases the effectiveness of 'feeding back' as 'feeding forward' provides an immediate chance of acting on advice. Thus, comments on drafts were more helpful than feedback on the final version after submission (ibid).

\subsubsection{Detailed Comments}

Detailed and longer text specific remarks were discovered resulting in more positive revisions (Ferris, 1997). Conrad \& Goldstein (1999), in their research on students feedback, discovered that comments dealing with details in the content were revised successfully by the students about half the time as opposed to superficial corrections such as spelling and formatting.

\subsubsection{Combined Feedback}

Conrad \& Goldstein (1999) \& F. Hyland (1998) noticed a close link between written and oral feedback observing that the points in written feedback can be better reinforced in student-teacher oral interactions. For many learners oral feedback following written feedback has the potential to allow for negotiation and interpretation of feedback (Hyland \& Hyland, 2006).Master (1995) found that feedback was effective when complemented with discussions. Goldstein and Conrad (1990) discovered that students who negotiated meaning in conferences were able to carry out better and extensive revisions to their writing than those who did not. Williams (2004) who found more uptake of teacher's advice when students negotiated and actively participated in the conferences also supported this finding.

\subsubsection{Negotiations and Interaction}

Williams (2004) points out that negotiation are crucial for text-based revisions. Patthey, Chavez \& Ferris (1997) examined some teachers' writing conferences with eight students and found a link between the topics discussed in the conferences and students subsequent revisions of their drafts. They discovered that all eight students utilised the tutor's suggestions in their revisions.

\subsubsection{Positive Feedback}


It is commonly proposed that feedback, including both positive and negative elements, will be more effective, with the former i.e. the positive comments enhancing the possibility of accepting the latter, i.e. the negative comments (F. Hyland \& K. Hyland 2001). The inclusion of a positive component (e.g. encouragement, praise) in a feedback has been asserted to contribute in mitigating the potentially negative impact of a negative feedback on motivation and self-esteem (Lizzio et al. 2003).

\subsubsection{Clarity of Feedback}

At the basic level, feedback needs to be clearly understood by the students if theyare to make use ofit (Lizzio\&Keithia, 2008). Students sometimes report difficulty about 'making sense' of comments (Norton \& Norton 2001) or 'translating' academic language (Chanock 2000). Besides, there is also some evidence suggesting apotential discrepancy between the meaning or intention of academics' feedback on assignments and its interpretation by students (Lea \&Steirer 2000).

\section{Methodology}

The data for this study data was collected within the Higher education context in UK. The study revolves around ten mixed international non-native ESL students doing M.A in modern languages in the Humanities Department belonging to different Asian and European countries.

The data was collected through "Qualitative interviews" (Rubin \& Rubin, 1995) in order to probe deeply into "people's more personal, private, and special understandings" (Arksey\& Knight, 1999: 4). Semi-structured interviews were used with the participants with an interview guide prepared beforehand (see Appendix A). Students were chosen by using convenient sampling method where "a certain group of people [were] chosen for study because they [were] available" (Fraenkel\&Wallen, 2003: 103). The interviewees were on the same course as mine and so were easily accessible to me. Secondly, I had already established good rapport with them required for interviews to effectively engage them in a reasonable discussion.

Detailed contextual and educational background of these students was not felt important to be provided because the purpose of the study is to elucidate the different perceptions held by these students about feedback practises and their background information might make them easily identifiable which goes against the ethics of research.

Students were requested to participate on the basis of their willingness and my understanding of their ability to contribute insights to the study. Interviews were then scheduled for a day and time according to the participant's convenience. The interviews were audio recorded with participants' permission. Consistent with the purpose of the study, questions in the interview guide focused on students interpretations of tutors' feedback, how they reacted toward those, which type of feedback practises they found useful in terms of informing their writing, what problems they confronted in processing those feedback. As is a common practise with semi-structured interviews, the sequence and exact phrasing of the questions were not fixed (Zhu, 2004). The general and already set up lead questions were asked first mostly followed up by more specific questions in order to elicit further information. At the end of each interview, interviewees were asked to comment, share or suggest anything they believed could be relevant to the study.

A total of ten interviews were collected, one from each respondent, each of which lasted from around 30 to 40 minutes. My role during the interviews was "to raise questions, rephrase the questions if necessary, listen to the responses, prompt for further information, ask for clarifications, check with the interviewees my interpretation of their responses, and answer respondents' questions (ibid: 33).

\section{Data Analysis}

The audio-recorded interviews were then transcribed and analysed followed by coding and categorisation of data. The prominent themes and patterns were identified. The interview data were 
analysed by utilising procedures recommended by Arksey \& Knight (1999) for analysis of qualitative interviews. First, a representative sample of two interviewees comments were analysed and initial coding content categories were developed. The resultant initial coded categories were then applied to the rest of sample i.e. to the comments of the other three students. I would analyse each theme followed by comparing evidence from the other data sets. In order to create sense of the themes, I followed the recursive "process of interpreting data, drawing tentative conclusions and returning to the raw data to seek evidence which confirmed or disconfirmed a particular line of thinking" (Carless, 2006: 222). Several categories emerged as a result of transcripts coding which is mentioned and explained below in discussion. After having developed an argument from the themes, I reported to the respondents aspects of the data that I found surprising, puzzling, or interesting asking them to judge my interpretations or elaborate their views thus using their point of views to increase the authenticity of my research findings (ibid)

\section{Findings and Discussion}

The analysis of the interviews transcripts revealed that interviewees, similar to the previous research findings (e.g. Poverjuc, 2011) received feedback in varied modes. However, in this study feedback was received mostly in written form from tutors and after the submission of assignments and less in oral form, from peers, during the writing processes and before the submission of assignments. Further, these transcripts indicated that the feedback aimed at mainly providing comments on their weaknesses in the current assignment. Three main themes emerged from the above-mentioned analytic procedures. These were; students' perceptions of different types of feedback practises, difficulties confronted by them in its successful use, and their perceptions of effective feedback practises. These themes have been "discussed separately for convenience of exposition, but there is also considerable interplay between them, with some points carrying relevance for more than one theme" (Carless, 2006: 223) also reflecting few concerns recognised in the broader feedback literature. In order to maintain participants' anonymity, they have been identified with capital alphabets. Although, the transcripts contain a lot of other useful insights about feedback practises all of which are not possible to be mentioned and discussed here on account of space constraints and so a much focused discussion is provided here. Thus, few quotations relevant to the research focus have been included at relevant places instead of the whole transcription.

\subsection{Students' Perceptions of Feedback Practices on Academic Assignments}

Consistent with the previous research findings, all the ten participants in this study showed their satisfaction with the idea of feedback practises in terms of indirectly improving their writing in the long run by informing them of their shortcomings in the current assignments. According to them, they would revisit their assignments particularly when the current assignment would have a similar requirement or section to that of the previous one. One student reported that in order to improve the current work, if he had performed well in a specific area in some previous assignment, he would try to use it in another assignment. For instance, once he obtained a useful feedback from his tutor regarding referencing, and he then used that assignment as a sort of template for future trials at referencing.

Definitely yes they [comments] were useful because they showed me what mistakes I did and what I forgot about and what would help me to avoid committing the same mistakes in the next assignment. Once I got a comment on how to make reference so [...] in my following assignments I was very careful about referencing and did correct referencing (A).

Feedback helped me in future assignments. When you do the next assignment, you remember that it was incorrect in previous assignment; so you avoid repeating it again just as I gave you referencing example. (A)

Another student reported that her old assignments had helped her a lot in improving her subsequent assignments.

Of course the feedback has helped me a lot in my other assignments. I have a clear idea about what my tutors are looking for and want of me. (D)

These excerpts reveal that students learnt to extend their current competence through the guidance of a 
more knowledgeable expert (Vygotsky, 1978). All the ten students (just three students are quoted for special reasons) acknowledged the fact of using their written feedback for feed-forward purposes in subsequent assignments such as regulating their writing behaviours and informing their following assignments in the light of previous feedback (Poverjuc, 2011).

In terms of type, mentioned below are few quotes from participants which along with their perceptions about feedback practices in general also show their preferences for and satisfaction with direct, written, detailed and content focused tutors' feedback consistent with the previous research findings. These types are categorized separately for greater readability.

Direct feedback: By direct feedback, I mean feedback which explicitly highlights and criticizes the problem whilst indirect feedback suggests reconsiderations or hedges criticism. Two students exhibited their liking for direct feedback as they felt it easy to process it and does not require many efforts to understand what is required of them.

I always liked direct feedback. I don't like feedback which requires lot of thinking as comments in question form provided by some tutors as I found it hard to reach to the right answer; so it would be better if tutor directly tell me the point. (D)

I will go for direct feedback as I don't want to be left wandering about issues in the writing (E). The words "wandering" and "lot of thinking" suggest their avoidance of mental exertion required in reflection on feedback.

Written: Two students' favoured written feedback more, possibly due to the fact that oral feedback is hard to remember as evidenced from the following quote. For example;

I will not go for it [oral feedback] because sometimes you change your mind during writing up of assignments and sometimes you forget what the guideline is, what the teacher wants you to do exactly $(\mathrm{B})$.

Or possibly because they can relate written feedback with their written work recursively at any time as it stays permanently as verified below by a student;

Written feedback for me is better as I can go through and check my assignments and see what I did was ok or not (A).

Negotiation: Two students showed their desire for discussion on feedback they receive. For example one student reported;

For me oral feedback is good as I can discuss my ideas with them [tutors] (B).

Here I will interpret 'Oral' to mean discussion based on the meaning in this sentence.

The other said;

Feedback makes a sense and is more fruitful when you discuss it thoroughly (C).

Detailed: Most students showed their desire to have even more detailed feedback, particularly feedback helping them in identifying problems and giving them information about academic expectations. Two of my participants affirmed the same fact as revealed in their responses such as;

Those with more details will be helpful which could tell me some solution about how to correct and improve my mistake (A).

I go for detailed comments which could give me some idea how to remove my mistakes and how

I can improve (B).

Content: One of my interviewee regarded content feedback more valuable for her as is visible from her quote;

For me the most important thing is the content feedback. It is something that makes sense actually for improving my writing and teaches me writing skill (E).

By content, when asked, she meant relating to structure and ideas.

\subsection{Difficulties in Using Feedback}

Also, my research findings confirm the research findings regarding difficulties. But here again the 
findings are divided into more detailed categories for clarity though the results are almost similar. In response to the questions asking students to identify problems or hurdles in using feedback, students indicated some feedback aspects as representing barriers in its effective use such as;

\subsection{Lack of Sufficient Feedback}

Two students described their experience of feedback mostly as limited which does not tell them much about their weak areas.

Comments on the assignments seem more of assessment and less of a tool to help us to improve our writing. Comments are to the point and limited (D).

Those with more details will be helpful which could tell me some solution about how to correct and improve my mistake (A).

This might be due to institutional constraints and responding to the assignment in terms of assessed piece of work that students hardly receive feedback other than a grade(Carless, 2006).

\subsection{Nature of Feedback}

Three students found it harder to grasp what the tutor meant by a certain comment because of the language and handwriting. For example, one student expressed it as follows:

I try to make sense of the comment but sometimes it's so vague and general that I can hardly understand what they want to say. It's very disturbing. (A)

Sometimes I cannot read some written comments that the marker writes, so I don't know and don't understand what the marker wants me to do, the language is not clear [...] In order to find them helpful, I should be able to read and understand them so the language should be clear to me in order to get benefit of those comments $(\mathrm{E})$.

I at times found the handwriting incomprehensible when feedback was given on the hardcopy. (D)

\subsection{Variation in Tutors' Preferences}

Two students showed strong reservations about different tutors marking things differently.

Sometimes one tutor says why I quoted old sources, and when I use recent sources in another assignment then the tutor says why I did not not make any reference to some old source (C).

Once one tutor gave me feedback to pay attention to structure. The other said structure is not that important but the ideas $(\mathrm{E})$.

\subsection{Lack of Connection between Assignments}

Two students commented that tutors' comment had not really helped them much in improving their writing as they were specific to the current assignment and so was not of much use to provide support for doing better in other assignments for different modules. One student's quote is presented here as example;

Well every assignment is different from the other. I didn't find that feedback useful which talks just about assignment that is checked. Most comments I have got were about the ideas in my current submitted assignment and not about the organisation, layout, logical sequence which could improve my writing in the long run as feedback about ideas are just limited to that particular assignment and ends with that (C).

\subsection{Unavailability of Feedback on Drafts}

When asked whether they approach tutors on their own, one student responded that

Initially I had been trying to get tutors consultation on drafts assignments but they showed little interest, Ifeel them usually avoiding. May be they are very busy; so they stop trying then or they may think that few students are receiving more support than others. (B)

Tutors are usually busy to allow us to discuss our ideas before submitting assignments $(\mathrm{C})$.

Providing detailed feedback might be difficult because of large class sizes and lack ofsufficient time (Carless, 2006). 


\subsection{Students' Perceptions of Effective Feedback}

Effective feedback was perceived in four main forms: Comments on drafts, related to transferable skills, combined feedback, some positive comments when providing critical comments and recognizing effort invested by students. Respondents associated positive feedback to their resultant motivation level.

Tutors' advice on draft assignments were believed by these students as a particularly significant source of 'feed forward' (Higgin et al., 2002) as providing an immediate chance of acting on advice. They further argued that comments on drafts were more helpful than feedback on the final version after submission. This belief was expressed in the following comment made by a student.

Feedback before the submission would be better as I can go through those comments and will take care of them and will take them seriously [.....]. I will use all comments during the assignment $[\ldots . .$.$] . (B)$

One student mentioned below also stated that if a teacher had spent some time commenting on drafts before the submission, they would expect briefer feedback to be given on the final version which proves utilisation of feedback on the part of student.

If I get feedback before submission, then I expect just few comments after the submission because I will use all comments, all feedback during doing my assignment; so I will not expect many comments after the submission of my assignments (A).

End or sing the significance of feedback supporting transferable learning, one student remarked that feedback could be more beneficially directed to general skills which can be transferred to other contexts such as paragraph development, cohesion and coherence, logical organization, clarity and conciseness, sentence structure, mechanics, citations and referencing. This supports a point forwarded by Knight and Yorke (2003), that although many tutors give a lot of feedback on specifics, it is the general feedback that has more power to stimulate learning. Such feedback possesses the potential to 'feedforward', into following tasks instead of feeding back into the completed assignments.

I didn't find the feedback useful as I rarely found comments about the organisation, layout, logical sequence which could improve my writing in the long run as feedbacks are just limited to the topic in that particular assignment and ends with that $(\mathrm{C})$.

\subsection{Combined Feedback}

Three students favoured consultations and discussions after they got marks on final assignments. For example,

It would be valuable if the tutors talk to us and discuss about our assignments after marking. I think it would be more effective for our development and learning $(\mathrm{C})$.

\subsection{Positive Comments}

Regarding positive comments two students reported;

I really appreciate some positive comments even if my assignment is not completely up to their expectations as it really keeps my motivation intact as I have invested a lot of time on it and definitely expect at least some reward (E).

I do a lot of hard work on assignments and do expect some acceptance of it in return (D).

Higgins et al. (2001), points out that 'the student makes an emotional investment in an assignment and expects some "return" on that investment' (p. 272) and negative feedback can be threatening to students' motivation.

The data gathered and analysed in this study echo confirmed most of the findings highlighted in the previous research in respect of students' appreciating the practises of feedback and facing almost the same issues with regard to the sources of difficulties in processing feedback. This includes the nature of feedback, language employed by the tutors, appropriate timings, individual differences and variations in tutor's preferences for marking. However, unlike previous research, my findings did not suggest cultural differences as a hurdle for the participants. This might possibly be because my study was not in depth enough to reveal such concerns or it might be due to the small sample size to attribute differences to 
culture. Beyond that, my research findings also illuminated students' perceptions regarding effective feedback practises not addressed previously (to my knowledge). So, my study revealed some perspectives of students concerning effective feedback practises such as comments on drafts, combined feedback (written feedback followed by discussions), positive feedback and feedback related to transferable skills.

\section{Conclusion}

Interested by significance of feedback practices in improving students' writing and written texts, their development as academics and the issues regarding effectiveness of feedback and driven by my personal motivation, this small scale empirical study was carried out in order to analyze the perceptions and experiences of M.A international ESL students in a master's programme An argument was made on the basis of this study's findings about how the process of feedback could be possibly made more constructive, useful and effective. All participants expressed their satisfaction with such support (feedback) in improving their academic writing though they also showed some reservations in effectively exercising them. These results raised tutors' awareness, to some extent: 1) of the potential difficulties, attached with feedback practises, in the light of above mentioned students' experiences with different types of feedback and 2) the significance of creating various opportunities to make feedback practises more valuable by bearing in mind the above-mentioned students' perceptions of effective feedback practises. Results suggest that only one type of feedback in a single mode should not preferred rather multiple types of feedback adapted to individual students needs and context could be useful for students. Although, this is a very small-scale study with few participants providing just a glimpse regarding feedback practises so generalizations and big conclusions cannot be drawn from it. However, the study still provides useful insights, which becomes the basis for some of the following implications for practice.

\subsection{Some Implications for Practice}

Generally speaking, the present findings may offer some guidance about students' expectations of effective feedback practises which might serve to sensitize tutors regarding potential of valuable feedback. Some specific points worth-mentioning could be those of the tutors;

- The ones who aim at providing developmental feedback should try to balance 'assignment specific' comments with more 'transferable' feedback (Lizzio\&Keithia, 2008)

- The ones who aim at encouraging students might try not just to acknowledge achievements, but also to recognize the effort invested, regardless of outcomes (ibid).

- If tutors are constrained by time and workload, instead of organising one to one discussion session, could arrange about 30 mins whole-class optional tutorial for general feedback on the assignments which would possibly be more interactive and thus more useful (Carless, 2006).

- Regarding tutors choice of appropriate style and language in their feedback which can facilitate students' writing development, tutors require to weigh their selection of comments $(\mathrm{K}$. Hyland \& F. Hyland, 2006).

- If possible teachers should tailor their feedback to suit each student preferences and needs(Ferris et al., 1997; F. Hyland 2001).

- If tutors could spare some time and organise opportunities where feedback on assignments in progress may be provided, this would definitely be a valuable form of feedback such as those provided in LING 6001 at group level and in LING 6011 at individual level in my M.A course. This may invite further research seeking students' perceptions, who have received such support, regarding the effectiveness of such practises. There is also a need of carrying out in depth research on the said issues regarding feedback to reach some sound conclusions. 


\section{References:}

Arksey, H., \& Knight, P. (1999).Interviewing for social scientists. Thousand Oaks, CA: Sage Publications.

Chanock, K. (2000). Comments on essays: do students understand what tutors write? Teaching in Higher Education, 5(1), 95-105.

Conrad, S. M. \& Goldstein, L. (1999). Student revision after teacher written comments: Text, contexts and individuals. Journal of Second Language Writing, 8(2), 147-180.

David, C. (2006). Differing perceptions in the feedback process.Studies in Higher Education, 31(2), 219-233.

Dochy, F.J., \& McDowell, L. (1997).Assessment as a tool for learning.Studies in Educational Evaluati on, 23: 279-298.

Enginarlar, H. (1993). Student response to teacher feedback in EFL writing.System, 21(2),

$193-$ 204.

Fathman, A. K., \&Whalley, E. (1990). Teacher response to student writing: Focus on form content. In Kroll (Ed.), Second Language Writing: Research Insights for the

versus (pp.178-90). Cambridge: CUP.

Ferris, D. (1995). Student reactions to teacher response in multiple-draft composition classrooms.TESOL Quarterly, 29(1), 33-53.

Ferris, D. (1997). The influence of teacher commentary on student revision.TESOL Quarterly, 31(2), 315-339.

Ferris, D. (2006). Does error feedback help student writers? New evidence on the short- and longterm effects of written error correction. In K. Hyland \& F. Hyland (Eds.), Feedback in second language writing: Contexts and issues (pp.81-104). New York: Cambridge University Press.

Ferris, D. \&Hedgcock, J. (2005).Teaching ESL composition: Purpose, process, and practice. Mahwah, NJ: Lawrence Erlbaum.

Ferris, D., Pezone, S., Tade, C., \&Tinti, S. (1997). Teacher commentary on student writing: Descriptions and implications. Journal of Second Language Writing, 6(2), 155- 182.

Fraenkel, J. R., Wallen, N. E., \& Hyun, H. H. (1993).How to design and evaluate research in education. Maidenhead: McGraw-Hill HE.

Gibbs, G. \& Simpson, C. (2004).Conditions under which assessment supports students' learning.Learning and Teaching in Higher Education, 1, 3-31.

Gibbs, G., Simpson, C. \& Macdonald, R. (2003).Improving student learning through changing assessment-a conceptual and practical framework. Paper presented to EARLI conference. Padova.

Goldstein, L. (2001). For Kyla: What does the research say about responding to ESL writers. $\quad$ In T. Silva \& P. Matsuda, (Eds.), On second language writing. Mahwah, NJ: Lawrence Erlbaum, 7390.

Goldstein, L. (2006). Feedback and revision in second language writing: Contextual, teacher, and student variables. In K. Hyland \& F. Hyland (Eds.), Feedback in second language writing: Contexts and issues (pp. 185-205). New York: Cambridge.

Goldstein, L. \& Conrad, S. (1990). Student input and negotiation of meaning in ESL writing conferences. TESOL Quarterly, 24(3), 443-460.

Hedgcock, J. \&Lefkowitz, N. (1994). Feedback on feedback: Assessing learner receptivity to teacher response in L2 composing. Journal of Second Language Writing, 3(2), 141-163.

Hedgcock, J. \&Lefkowitz, N. (1996). Some input on input:Two analyses of student response to expert feedback in L2 writing. The Modern Language Journal, 80(3), 287-308.

Hester, V. (2001).Responding to student writing: locating our theory-practice mong

communities.

Paper presented at the 52nd Annual Meeting of the Conference on College Composition and Communication. Denver.

Hounsell, D. (1987). Essay writing and the quality of feedback.In J.T.E. Richardson, M. Eysenck, \& D.W. Piper Milton Keynes (Eds.), Student learning research in education and cognitive 
psychology. Buckingham: SRHE/Open University Press.

Hounsell, D. (2003). Student feedback, learning and development.In M. Slowey\& D. Watson (Eds.),

Higher education and the lifecourse. Maidenhead: Open University Press.

Higgins, R. (2000) 'Be more critical': rethinking assessment feedback, paper presented to British

Educational Research Association Conference, Cardiff University, 7-10 September. Retrieved on May 20 from: $\quad$ http://www.leeds.ac.uk/educol/documents/00001548.htm

Higgins, R., Hartley, P. \& Skelton, A. (2001).Getting the message across: the problem of communicating assessment feedback.Teaching in Higher Education, 6(2), 269-274.

Hyland, F. (1998).The impact of teacher written feedback on individual writers.Journal of Second Language Writing, 7(3), 255-286.

Hyland, F. (2000). ESL writers and Feedback: Giving more autonomy to students. Language

Teaching Research, 4(1), 33-54.

Hyland, F. (2001). Providing effective support: investigating feedback to distance language learners. Open Learning, 16(3), 233-247.

Hyland, K. (2000). Disciplinary discourses: social interactions in academic writing. London: Longman.

Hyland, F., \& Hyland, K. (2001).Sugaring the pill: praise and criticism in written feedback. Journal of Second Language Writing, 10, 185-212.

Hyland, K. \& Hyland, F. (2006).Feedback on second language students' writing.Language Teaching, 39, 83-101.

Hyland, K. \& Hyland, F. (Eds.) (2006).Feedback in second language writing: Contexts and issues. New York: Cambridge University Press.

James, D. (2000). Making the graduate: perspectives on student experience of assessment in higher education. In A. Filer (Ed.), Assessment: social practice and social product. $\quad$ London:

RoutledgeFalmer

Lea, M.R., \&Steirer, B. W. (2000). Student writing and staff feedback in higher education: an academic literacy approach. In M. Lea and B. Steirer (Eds.), Students' writing in higher education: new contexts. Buckingham: SRHE/Open University Press.

Leki, I. (1991). The preferences of ESL students for error correction in college level writing classes. Foreign Language Annals 24(3), 203-218.

Leki, I. (2006). "You cannot ignore": L2 graduate students' experience of and responses to written feedback practices within their disciplines. In K. Hyland \& F. Hyland (Eds.), Feedback in second language writing: Contexts and issues (pp. 266-285). New York: CUP.

Lizzio, A., \&Keithia, W. (2008). Feedback on assessment: students' perceptions of quality and effectiveness. Assessment \& Evaluation in Higher Education, 33(3), 263-275.

Lizzio, A., Wilson, K., Gilchrist, J., \&Gallois, C. (2003).The role of gender in the construction and evaluation of feedback effectiveness.Management Communication Quarterly, 16, 341-379.

Master, P. (1995). Consciousness Raising and Article Pedagogy. In D. Belcher \& G. Braine (Eds.), Academic Writing in a Second Language: Essays in Research and Pedagogy ～(pp. 183-205). Norwood, NJ: Ablex.

Norton, L.S., \& Norton, J. C. W. (2001).Essay feedback: how can it help students improve their academic writing? Paper presented at First International Conference of the European Association for the Teaching of Academic Writing across Europe (EATAW). Gronigen.

Orsmond, P., Merry, S. \&Reiling, K. (2005). Biology students' utilization of tutors' formative feedback: a qualitative interview study. Assessment \& Evaluation in Higher Education, 30(4), 369-386

Patthey-Chavez, G., \& Ferris, D. (1997).Writing conferences and the weaving of multi-voiced texts in college composition. Research in the Teaching of English, 31(1), 51-90.

Ramsden, P. (2003). Learning to teach in higher education (2nd ed). London: Routledge Falmer.

Robb, T., Ross, S. \&Shortreed, I. (1986).Salience of feedback on error and its effect on EFL writing quality.TESOL Quarterly, 20(1), 83-93.

Rubin, H., \& Rubin, I. (1995).Qualitative interviewing: The art of hearing data. Thousand Oaks, CA: Sage Publications. 
Saito, H. (1994). Teachers' practices and students' preferences for feedback on second language writing: A case study of adult ESL learners. TESL Canada Journal, 11(2), 46-70.

Vygotsky, L. (1978) Mind in Society: The Development of Higher Psychological Processes. Cambridge, MA: Harvard.

Williams, J. (2004). Tutoring and revision: Second language writers in the writing center. Journal of Second Language Writing, 13(3), 173-201.

Young, P. (2000). I might as well give up: self-esteem and mature students feelings about feedback on assignments. Journal of Further and Higher Education, 24, 409-418.

Zamel, V. (1985).Responding to student writing.TESOL Quarterly, 19(1), 79-101.

Zhu, W. (2004). Faculty views on the importance of writing, the nature of academic writing, and teaching and responding to writing in the disciplines. Journal of Second Language Writing, 13 , 29-48. 